\title{
Defining Respectful Leadership: What it is, how it can be measured, and another glimpse at what it is related to
}

\author{
Niels van Quaquebeke, and Tilman Eckloff
}

(Accepted for publication in Journal of Business Ethics)

\begin{tabular}{|l|l|}
\hline \multicolumn{2}{|l|}{ ERIM REPORT SERIES RESEARCH IN MANAGEMENT } \\
\hline ERIM Report Series reference number & ERS-2009-027-ORG \\
\hline Publication & May 2009 \\
\hline Number of pages & 34 \\
\hline Persistent paper URL & http://hdl.handle.net/1765/15942 \\
\hline Email address corresponding author & nquaquebeke@rsm.nl \\
\hline Address & Erasmus Research Institute of Management (ERIM) \\
& RSM Erasmus University / Erasmus School of Economics \\
& Erasmus Universiteit Rotterdam \\
& P.O.Box 1738 \\
& 3000 DR Rotterdam, The Netherlands \\
& Phone: + 31 10 408 1182 \\
& Fax: $\quad+31104089640$ \\
& Email: info@erim.eur.nl \\
& Internet: $\quad$ www.erim.eur.nl \\
\hline
\end{tabular}

Bibliographic data and classifications of all the ERIM reports are also available on the ERIM website: www.erim.eur.nl 


\section{ERASMUS RESEARCH INSTITUTE OF MANAGEMENT}

\section{REPORT SERIES}

\section{RESEARCH IN MANAGEMENT}

\begin{tabular}{|l|l|}
\hline ABSTRACT AND KEYWORDS \\
\hline Abstract & $\begin{array}{l}\text { Research on work values shows that respectful leadership is highly desired by employees. On } \\
\text { the applied side, however, the extant research does not offer many insights as to which concrete } \\
\text { leadership behaviours are perceived by employees as indications of respectful leadership. Thus, } \\
\text { to offer such insights, we collected and content analyzed employees' narrations of encounters } \\
\text { with respectful leadership (N1 = 426). The coding process resulted in 19 categories of respectful } \\
\text { leadership spanning 149 leadership behaviours. Furthermore, to also harness this } \\
\text { comprehensive repertoire for quantitative organizational research, we undertook two more } \\
\text { studies (N2a = 228; N2b = 412) to empirically derive a feasible item-based measurement of } \\
\text { respectful leadership and assess its psychometric qualities. In these studies, we additionally } \\
\text { investigated the relationships between respectful leadership as assessed with this new } \\
\text { measurement and employees' vertical and contextual followership as assessed via subordinates' } \\
\text { identification with their leaders, their appraisal respect for their leaders, their feeling of self- } \\
\text { determination, and their job-satisfaction. }\end{array}$ \\
\hline Free Keywords & $\begin{array}{l}\text { interpersonal respect, leadership, vertical followership, contextual followership, self- } \\
\text { determination, appraisal respect, identification, satisfaction }\end{array}$ \\
\hline Availability & $\begin{array}{l}\text { The ERIM Report Series is distributed through the following platforms: } \\
\text { Academic Repository at Erasmus University (DEAR), DEAR ERIM Series Portal } \\
\text { Social Science Research Network (SSRN), SSRN ERIM Series Webpage } \\
\text { Research Papers in Economics (REPEC), REPEC ERIM Series Webpage }\end{array}$ \\
\hline Classifications & $\begin{array}{l}\text { The electronic versions of the papers in the ERIM report Series contain bibliographic metadata } \\
\text { by the following classification systems: } \\
\text { Library of Congress Classification, (LCC) LCC Webpage } \\
\text { Journal of Economic Literature, (JEL), JEL Webpage } \\
\text { ACM Computing Classification System CCS Webpage } \\
\text { Inspec Classification scheme (ICS), ICS Webpage }\end{array}$ \\
\hline
\end{tabular}


Running head: DEFINING RESPECTFUL LEADERSHIP

Defining respectful leadership: What it is, how it can be measured, and another glimpse at what it is related to

\author{
Niels van Quaquebeke* \\ Rotterdam School of Management, Erasmus University
}

Tilman Eckloff*

RespectResearchGroup, University of Hamburg

(Accepted for publication in Journal of Business Ethics)

DOI : 10.1007/s10551-009-0087-z

* Both authors contributed equally to this publication. The author order was chosen randomly.

Keywords: Interpersonal Respect, Leadership, Vertical Followership, Contextual Followership, Self-Determination, Appraisal Respect, Identification, Satisfaction 


\begin{abstract}
Research on work values shows that respectful leadership is highly desired by employees. On the applied side, however, the extant research does not offer many insights as to which concrete leadership behaviours are perceived by employees as indications of respectful leadership. Thus, to offer such insights, we collected and content analyzed employees' narrations of encounters with respectful leadership $\left(N_{l}=426\right)$. The coding process resulted in 19 categories of respectful leadership spanning 149 leadership behaviours. Furthermore, to also harness this comprehensive repertoire for quantitative organizational research, we undertook two more studies $\left(N_{2 a}=228\right.$; $N_{2 b}=412$ ) to empirically derive a feasible item-based measurement of respectful leadership and assess its psychometric qualities. In these studies, we additionally investigated the relationships between respectful leadership as assessed with this new measurement and employees' vertical and contextual followership as assessed via subordinates' identification with their leaders, their appraisal respect for their leaders, their feeling of self-determination, and their job-satisfaction.
\end{abstract}


Most of us want to be respected by others. This holds true not only in our private life, but also at work (Mason, 1994; van Quaquebeke, Zenker, \& Eckloff, 2008). When we feel respected at work, especially by authorities, we are not only personally more satisfied, but also more likely to identify with the collective and exert effort on behalf of it (Boezeman \& Ellemers, 2008a; Lind \& Tyler, 1988; Simon \& Stürmer, 2003; Tyler \& Blader, 2000; Tyler, Boeckmann, Smith, \& Huo, 1997; Tyler \& Lind, 1992). Yet, despite the evidence that respectful leadership informs many positive organizational consequences and is likewise highly desired by employees, research shows that it is a rare experience at people's actual workplace (van Quaquebeke et al., 2008). In their paper, van Quaquebeke and his colleagues thus concluded that much organizational potential currently lies idle because many leaders have not yet adopted a respectful leadership style.

For those leaders, who want to adapt their behaviour, the extant research on respect, however, offers only limited insights into which specific leadership behaviours would lead to subordinates perceiving themselves as being treated with respect. Indeed, most of the studies in this field use experimental paradigms, which are hard to translate into the managerial world, or they use short item lists (such as "I feel respected for my work" or "I feel respected as a person"), which capture the feeling of being respected but not the leader's behaviours and attitudes that contribute to such a feeling.

As an answer to this void, the objective of the present paper is a) to present insights as to what respectful leadership actually is, b) to offer a feasible measure for the same to be used in future organizational research, and c) to use this measure to investigate some more of the effects of respectful leadership on subordinates. We hope that in doing so, we will continue to inform the discussion for why respectful leadership is an important aspect to consider in organizational 
practice, inform research as to how respectful leadership can be measured, and finally inform leaders as to what they could actually do to be perceived respectful.

$$
\text { Interpersonal Respect - A Theoretical Introduction }
$$

In line with the general tenets in the philosophical traditions of respect research (cf. Dillon, 2003, 2007; Hill, 1998; van Quaquebeke, Henrich, \& Eckloff, 2007), we define respect as a person's attitude towards other people, in whom he/she sees a reason that, in itself, justifies a degree of attention and a type of behaviour which in return engenders in the target a feeling of being appreciated in importance and worth as a person. The aspects that underlie this definition of respect need to be discussed in more detail:

A person who respects others, notices others. The Latin roots of the term respicere, the etymological origin of the word respect, can be translated literally as to look back to or to look again, in a wider sense to consider, to notice. This form of noticing and seeking to understand a person can therefore be described as a form of recognition (Dillon, 2003). Noticing other people means recognizing their importance and value. It means actively confronting oneself with the task to find out who or what they "really" are. Respect thus aims for an accurate assessment of the other person. This includes being consciously aware of the presence of the other person in one's own environment, recognizing his or her role appropriately in the context of the situation, and correctly understanding the mutual relationship.

A person who respects another person, perceives a reason in the other person that justifies this respect in itself. Respect is owed, a person can earn respect, or he/she has a quality that calls for respect. The everyday use of the term indicates that the object of one's respect possesses certain qualities or markers that justify recognition and an appropriate, respectful reaction. The other person offers "good reason", as it were, for respecting and appreciating that 
he/she has a legitimate claim for our recognition and appreciation in terms of what he/she is. This reason is absolute, in the sense that its importance and significance do not depend on our own interests, ambitions, or needs. It affects our will immediately without being influenced by our inclinations (Rawls, 1999). In other words, a respectful action is voluntary, but one would feel disingenuous if one acted against this cause and the logic it establishes (cf. Birch, 1993; Raz, 2001; Sennett, 2003). This also means that respect fulfils Kant's conditions for the categorical imperative (Kant, 1788), i.e., perceiving the other person as an end in itself and not merely as a means to an end. If somebody behaves respectfully exclusively or to a predominant degree for reasons of usefulness of the other person for reaching own ambitions or satisfying own needs, it would not be called respect.

A person who respects another person acts in such a manner that it in return engenders a feeling in the other person of being appreciated in his/her importance and worth as a person. According to Spears, Ellemers, and Doosje (2005), respect entails an appreciation for the other person that is communicated in one's own behaviour. In the sense of this definition, respect can therefore be described as a process that is aimed at recognizing, appreciating, and communicating the importance and worth of the other person. Put differently, respect entails maintaining an appreciative attitude towards the other person and acting on the basis of this attitude (Downie \& Telfer, 1969; Frankena, 1986) even if one does not personally like or agree with the object of respect (Simon \& Stürmer, 2003; Spears et al., 2005). However, talking somebody down or flattering him/her, for reasons that that person does perceive to be true, cannot be called respect (Anderson, 1993; Pettit, 1989).

\section{Interpersonal Respect in Organizations}

The value of respect has gained considerable public recognition over the recent years. 
Particularly, a lack of respect and the absence of genuine appreciation for other people are seen as a cause for many problems in the social sphere (Margalit, 1998; Miller, 2001; Sennett, 2003). It is thus unsurprising that respect has gaining ever more ground as an object of research in the field of social psychology as well as organizational behaviour.

Studies have, for instance, shown that organizational commitment and adherence to organizational rules can be improved if its representatives demonstrate respect in the treatment of others within that organization (Boeckmann \& Tyler, 2002; Boezeman \& Ellemers, 2008a; Lind \& Tyler, 1988; Tyler \& Blader, 2000; Tyler et al., 1997; Tyler \& Lind, 1992). Likewise, being treated with respect has been shown to evoke a heightened degree of group serving behaviour in individuals' in-role and extra-role organizational behaviour (Simon \& Stürmer, 2003, 2005; Tyler \& Blader, 2000). This commitment towards one's group even occurs if individuals receive a simultaneous message of disliking (Spears et al., 2005), a message of group exclusion (Simon \& Stürmer, 2005), or negative performance evaluations (Simon \& Stürmer, 2003). Further research also revealed that people who were respected seem to lose concern for their personal image and rather engage in efforts to improve their group's image if it is under threat (Branscombe, Spears, Ellemers, \& Doosje, 2002). Overall, many of these positive effects can be argued to be traced back to a sense of heightened self-worth that seems to be embedded in the commutation of respect (De Cremer \& Tyler, 2005; Smith, Tyler, Huo, Ortiz, \& Lind, 1998; Tyler \& Blader, 2000). In contrast, disrespect often entails a message of inequality and lesser worth (Simon, 2007; Simon, Lücken, \& Stürmer, 2006; van Quaquebeke et al., 2007) which is then reciprocated with deviance, anger, and aggression (Bettencourt \& Miller, 1996; Cohen, Nisbett, Bowdle, \& Schwarz, 1996; Miller, 2001) and a generally more self-focussed attitudinal and behavioural response (Sleebos, Ellemers, \& De Gilder, 2007). 
Considering these findings, one can arguably propose that the question of interpersonal respect between leaders and their subordinates is highly relevant for productive cooperation in organizations, and even more so in contexts that rely strongly on committed and cooperationminded employees (Boezeman \& Ellemers, 2007, 2008a, 2008b). Research even goes so far as to suggest that respectful treatment by authorities is at times an even more powerful means to foster vertical and horizontal cooperation, i.e., subordinates' cooperation with leaders and their peers, than any anticipated monetary returns (De Cremer, 2003; Ellingsen \& Johannesson, 2007).

Furthermore, studies regarding the effects of interpersonal respect at the workplace are triangulated by research on work values. These studies show that respect also figures as a key value in employees' work value rankings, beating issues such as job security and higher income opportunities (Mason, 1994; van Quaquebeke et al., 2008). Most importantly for the present study, these previous studies have shown that employees foremost care about a respectful treatment by their leaders. In stark contrast to this desire, however, the research by van Quaquebeke et al. (2008) also shows that experienced organizational practices diverge strongly negative, in that respectful leadership is highly desired but hardly encountered (highest rank difference among 18 work values).

Leaders in practice, however, will find it hard to obtain concrete insights from the extant research as to how they should change their behaviour, i.e., which concrete behaviours or attitudes would convey a sense of respect. Indeed, as stated above, most of the studies in this field use experimental paradigms which are hard to translate into the managerial world, or they use short items which capture the feeling of being respected but not the perceived leadership behaviours and attitudes behind it. 
The Present Set of Studies

We opted for a multiple-study, multi-method approach to investigate the topic of respectful leadership from different angles. Study 1 was undertaken to explore what employees consider respectful leadership. Due to the explorative nature, we used a qualitative approach to gather and comprehensively analyze the data. The results of this study subsequently served as the basis of two quantitative studies, Study $2 \mathrm{a}$ and $2 \mathrm{~b}$, in which we sought to reduce the previously gathered extensive respectful leadership inventory to a more feasible item list that could be used in organizational research. Instead of one study, we decided to conduct two studies to ensure that identified psychometric properties and relationships with other variables are replicable.

Study 1

\section{Method}

\section{Sample}

The study was conducted in Germany. In order to reach a broad cross-section of the working population and to avoid strong selection biases, a multi-site-multi-entry strategy was chosen for recruiting survey participants, i.e., participants were recruited on diverse online portals employing a variety of entry types (teaser text boxes, banners, or short articles about the study).

In total, 426 employees participated in the qualitative survey. The average age of the participants was $38(S D=11.00$ years). The gender ratio was balanced, with $48 \%$ female participants. About a third of the test subjects had higher educational qualifications. On average, the participants had already worked for 15 years ( $S D=12.78$ years), with an average of four different employers. They had worked under an average of seven different leaders in this time $(S D=5.67$ leaders $)$. 


\section{Measures}

Central to the purpose of the present study, participants were surveyed about their encounters with respectful leadership. They were asked to name and describe critical incidents in which they felt truly respected by their leader. The participants were told that these examples could be drawn from experiences with different leaders and that they could list as many as they wanted to. Each description of such a critical incident was to be entered in a dedicated text box, formatted to a size that used up a considerable part of the screen to stimulate detailed answers.

\section{Data Analysis Procedure}

The qualitative data on respectful leaders was subjected to an explorative content analysis based on qualitative content analysis paradigm of Mayring (2000) as well as the principles and methods of Grounded Theory (Strauss \& Corbin, 1998). Since these procedures can be used in slightly different ways, it is generally advised to make the procedure fully transparent for sakes of replication - which we will thus do in the following:

In a first step, the answers given by a single participant were split into "one-dimensional" analytical units. If the answers given by the participants were already structured by bullet points or paragraphs, this "natural unit structure" was initially maintained. Each unit was then reviewed to ascertain whether it carried one central meaning, in which case it was maintained as an analytical unit, or indeed included a number of significant dimensions, which suggested further subdivisions. A subdivision was not performed when additional information only contextualized the main unit of meaning, such as specifying the condition, an addition, or explanation. In other words, the smallest text fragment to be defined as an analytical unit could, for instance, be a single word, such as "trust", or it included conditions, explanations, and additions and would thus be an entire description of a situation in which a leader displayed trust in the participant. All 
in all, this approach produced 1363 analytical units.

A second step focussed on the repeated pairwise comparisons of these analytical units and their inductive allocation by way of similarities into initially very broad categories. Via this process, we defined 21 superordinate categories that offered a first sense of direction. Both the categories and the allocation of the analytical units to these categories were not regarded as definite, so that the initial allocation and labelling could be changed as required over the course of the coding process. Throughout the process, we kept a coding protocol in which we recorded questions, assumptions about possible relationships, and our thoughts about the identified categories.

In a third step, the identified broad categories were subjected to closer scrutiny. Subcategories were developed by applying the same method of comparison, coding, and reversible, inductive categorization. Altogether, this process was primarily aimed at establishing internal stringency and unambiguousness in the subcategories.

In a fourth step, we reviewed and, if required, adjusted the categories to establish coherence among the categories and the allocated analytical units. This approach produced 94 subcategories that were, in turn, compared to one another and grouped inductively according to their similarity, which allowed for a comparison to and adjustment of the original superordinate category system. The result was a revision of the 21 superordinate categories into 19 categories and one category of analytical units that defied categorization. Subsequently, to investigate interrater agreement, another independent rater was given the broad descriptions of the $19+1$ categories and was then asked to repeat the allocation of the 1363 analytical units to the identified 19+1 categories of respectful leadership behaviour.

Finally, standardized statements were formulated, category-by-category, for all 1363 
analytical units, merging all clearly redundant units within the categories. The standardization of the statements included further that the leader was always the subject who displayed a certain respectful attitude or behaviour towards the participant from an ego-participant perspective. In this way, the number of statements was reduced to 149 .

\section{Results}

Our content analysis of narratives of critical incidents in which participants felt truly respected by their leaders led to the definition of 19 categories of respectful leadership, each reflecting one specific behavioural or attitudinal aspect. The categories are: Trusting, Conferring responsibility, Considering needs, Maintaining distance, Appreciating, Being error-friendly, Granting autonomy, Acknowledging equality, Promoting development, Being open to advice, Accepting criticism, Excavating potential, Seeking participation, Taking interest on a personal level, Being reliable, Being attentive, Supporting, and Interacting friendly.

To investigate inter-rater agreement concerning the allocation of the initial 1363 analytical units to these categories of respectful leadership, Cohen's Kappa ( $)$ was calculated (cf. inter-rater agreement for nominal data in Brennan \& Prediger, 1981; Thompson \& Walter, 1988). As a rule of thumb a $\kappa>0.75$ is generally considered an indicator for good levels of agreement. In the present case, the ratings match exceptionally well $(\kappa=.982, t=135.22, p<$ .001 ), thus bolstering our confidence in the category system. The 19 categories and the respective 149 standardized statements of respectful leadership are shown in Appendix A.

Study $2 \mathrm{a}$ and $2 \mathrm{~b}$

The primary purpose of the second set of studies was to reduce the previously gathered extensive inventory for respectful leadership to a more feasible item list that could be used in organizational research. Instead of one study, we decided to conduct two studies to check 
whether identified psychometric properties and relationships with other variables could be replicated. In addition to this reduction process, across both studies, we sought to explore the effects of perceived respectful leadership on subordinates' vertical and contextual followership.

Vertical followership, means that, in the best case, subordinates are voluntarily open to their leaders' influence (cf. Chemers, 2003; B. van Knippenberg \& van Knippenberg, 2003; Yukl \& Van Fleet, 1992). If happening consciously, this can, for instance, be read as subordinates' appraisal respect for their leaders (cf. Dillon, 2003; van Quaquebeke et al., 2007). Or, if it takes place on a more subconscious level, it can be argued to be reflected in subordinates' identification with their leaders (Kelman, 1958; Shamir, House, \& Arthur, 1993; D. van Knippenberg, van Knippenberg, De Cremer, \& Hogg, 2004).

Contextual followership, means that, in the best case, subordinates perceive a sense of self-determination in their doing (autonomy, relatedness, and competence - see Deci \& Ryan, 2000; Gagné \& Deci, 2005) which enables them to react proactively and independently in the ever changing organizational environments (cf. Baard, Deci, \& Ryan, 2004; Organ, Podsakoff, \& MacKenzie, 2006). Apart from these issues of followership, subordinates' general job satisfaction was assessed as an additional dependent variable because it is a good reverse proxy for organizational role ambiguity and role conflict (Goldstein \& Rockart, 1984) both of which can potentially threaten the effective functioning of an organization.

Given the extant literature on the effects of interpersonal respect on group commitment (e.g., Boezeman \& Ellemers, 2008a; Simon \& Stürmer, 2003; Simon \& Stürmer, 2005) and rule adherence (e.g., Tyler \& Blader, 2000, 2003), we can assume all of these independent variables to be positively related to perceptions of respectful leadership. Indeed, it seems that it should be easier for individuals to open up for someone's leadership if they feel that they are being treated 
respectfully in the leadership process. Likewise, it seems highly plausible that respectful leadership will also positively relate to employees' perceptions of self-determination with its facets of autonomy, competence, and relatedness (Deci \& Ryan, 2000). Indeed, the behavioural repertoire generated in Study 1 encompasses categories which directly map onto these basic human needs, e.g., appreciating, maintaining distance, or showing loyalty, which suggests that respectful leadership might be exactly about satisfying basic human psychological needs as defined by Deci and Ryan (2000). Finally, given previous studies that show that respectful leadership is highly desired but hardly experienced in real life (van Quaquebeke et al., 2008), we also believe that, once it is encountered in organizational practice, employees will be very satisfied with their job.

\section{Method}

\section{Sample $2 a$}

Participants for Study 2a were recruited by the same means employed in Study 1. In total, 228 people participated in the survey. The average age of the participants was 37 ( $S D=10.17$ years), with $58 \%$ female and $42 \%$ male participants. $54 \%$ of the survey participants had higher educational qualifications. On average, they had spent 16 years $(S D=10.17$ years) under six different superiors $(S D=3.95) .30 \%$ of the participants had a female superior and $70 \%$ a male superior at the time of the survey. The professional background of the participants ranged over a total of 43 different areas of industry, from warehouse workers to university teachers.

Sample $2 b$

Participants for Study $2 \mathrm{~b}$ were recruited by means of a German consumer panel (Sozioland). The sample includes 412 participants. The average age of the participants was 35 ( $S D=10.17$ years) with $64 \%$ female and $36 \%$ male participants. $48 \%$ of the participants had 
higher educational qualifications. On average, they had already worked 15 years $(S D=10.06$ years) under six different superiors $(S D=5.14) .30 \%$ of participants had a female superior at the time of the survey, compared to male superiors for $70 \%$ of participants. The range of professional backgrounds covered 42 different areas of industry from warehouse workers to business consultants.

\section{Measures $2 a$ and $2 b$}

First, participants were requested to rate all of 149 standardized respectful leadership statements in terms of how important the described behaviour is for them to feel respected by their leaders ("How important are the following leadership behaviours in order for you to feel respected by a leader?"). Answers were to be made on a seven-point Likert scale from 1 (not important at all) to 7 (very important). Second, participants were asked to rate their current leaders in terms of all 149 standardized respectful leadership statements ("My leader ..."). The degree to which participants' perceived their current leaders to exhibit such behaviours were assessed on a five-point Likert scale from 1 (not at all) to 5 (very much). Finally, we asked participants to indicate the degree to which they felt respected by their leader via a so called marker item that would be used in the later item selection procedure ("If you think about your current leader, how strongly do you feel respected by him/her?"). The answer was to be made on a five-point Likert scale from 1 (not at all) to 5 (very much).

For the assessment of participants' identification with their leader, an adapted version of Mael and Ashforth's (1992) organizational identification questionnaire was employed, using the participant's current leader as the target of identification (cf. van Dick, Wagner, Stellmacher, \& Christ, 2004). This scale contains items such as: "If someone criticizes my leader, it feels like a personal insult." or "I am very interested in what other people think about my leader". Degree of 
agreement was ranked for each item on a five-point Likert scale from 1 (do not agree at all) to 5 (agree completely).

Participants' appraisal respect for their leaders was assessed via six items (Graf \& van Quaquebeke, 2007; van Quaquebeke \& Brodbeck, 2008). The scale items were (1) "For me, my leader represents a positive role model at the workplace.", (2) "I trust the judgment of my leader in work issues.", (3) "In a lot of matters concerning work I gladly seek advice from my leader.", (4) “At work I enjoy being able to learn from my leader.", (5) "Due to the influence of my leader I feel very constricted in my professional development." [reverse coded], (6) "I owe respect to the way my leader accomplishes his / her professional functions." Degree of agreement was ranked for each item on a five-point Likert scale from 1 (do not agree at all) to 5 (agree completely).

Participants' perception of self-determination in the relationship with their leaders was assessed with the basic needs satisfaction in relationships scale (La Guardia, Ryan, Couchman, \& Deci, 2000). This scale assesses the extent to which a person perceives his/her basic psychological needs for autonomy, competence, and relatedness to be satisfied in the relationship with another person. It contains items such as: "In the interaction with my current leader, I have a say in what happens, and I can voice my opinion." (autonomy), "In the interaction with my current leader, I very capable and effective." (competence), "In the interaction with my current leader, I feel a lot of closeness and intimacy." (relatedness). Degree of agreement was ranked for each item on a five-point Likert scale from 1 (completely disagree) to 5 (agree completely).

Participants' job satisfaction was surveyed via Kunin's 7-point satisfaction scale (1955) ranging from very unhappy (1) to very happy (7) smiley faces. It covers seven aspects of job satisfaction, i.e., the satisfaction with one's colleagues, with one's leader, with one's duties, with 
one's working conditions, with one's organization and management, with one's development opportunities, and with one's remuneration. As advised by Kunin (1955), the mean across these seven aspects is used as the score for general job satisfaction.

\section{Results $2 a$ and $2 b$}

To reduce the 149 items (as depicted in Appendix A) to a more economic but also representative list of items regarding respectful leadership, we first investigated which of the 149 items was attributed at least an importance score of 6 on the scale from 1 (not important at all) to 7 (very important) in order to feel respected by a leader (see Table 1, first column). Additionally, the items were supposed to highly correlate $(r>.6)$ with the respectful leadership marker item (“If you think about your current leader, how strongly do you feel respected by him/her?”). Of the remaining items, and if more than one item within a category fulfilled the criteria, we subsequently chose that item within each category that applied to a wider array of situations and which at the same time indicated a concrete leadership behaviour or attitude towards a subordinate. Using these criteria for the selection of the items, a total of twelve items were identified for the respectful leadership scale. The final items are: 1) “... trusts my ability to independently and self-reliantly perform well.”, 2) “... expresses criticism in an objective and constructive way.”, 3) “... recognizes me as a full-fledged counterpart.”, 4) “... recognizes my work.”, 5) “... shows a genuine interest in my opinions and assessments.”, 6) “... does not try to hold me responsible for his/her own mistakes.”, 7) “... unequivocally stands up for me and my work against third parties.”, 8) “... treats me in a polite manner.”, 9) “... provides me with any information that is relevant to me.”, 10) “... takes me and my work seriously.”, 11) “... interacts in an open and honest way with me.”, 12) “... treats me in a fair way.”

Item 6 was selected from the category "Accepting criticism", despite the fact that it has a 
correlation below .6 with the marker item in Study 2a (see Table 1, fourth column). We chose to include it because participants generally rated items of this category as highly important in order to feel respected by their leaders. Without this inclusion, the entire category would not have been represented in the scale. Furthermore, in Study 2b, the correlation meets the required criteria. [Insert Table 1 about here]

In a next step, we examined the psychometric qualities of the identified 12 items to ensure that our respectful leadership scale is of sound quality when applied with regard to actual leaders (see further in Table 1). First, we employed a principal component factor analysis to explore the extent to which the 12 items represent a one-dimensional structure. Both studies confirm the one-dimensional nature of the scale, in that the principal component analyses revealed only one factor with an Eigenvalue of above 1. In Study 2a, this factor was responsible for $68.3 \%$ of the variance. In Study $2 b$, it was responsible for $66.8 \%$ of the variance. In both studies, the separate factor loadings for each of the 12 items were higher than .6. Second, discriminatory power scores were calculated for all items. All 12 items exhibited sufficient discriminatory power $(>.5)$. Third, the scale's internal consistency was examined and shown to be very good in both studies (Cronbach's Alpha $=.96$ in Study 2a, and .95 in Study 2b). Splithalf reliability is similarly positive, at .95 for both studies. Together, these findings leave us confident to continue with these 12 items as a satisfactory scale to assess respectful leadership.

Further investigations within the present datasets show that this scale is neither skewed by participants' work experience nor gender issues. In both studies, female participants rated their leaders in a fashion similar to their male counterparts (Study 2a: $t(226)=1.08, p>.05$; Study $2 \mathrm{~b}: t(410)=1.52, p>.05)$. This not only suggests the absence of a gender-based bias in perceptions of respectful behaviour, but also that leaders' respectful behaviour towards women 
and men does not differ. Likewise, female leaders received on average a similar respectful leadership rating as their male counterparts (Study 2a: $t(226)=-0.19, p>$. 05; Study $2 \mathrm{~b}: t(410)=$ $0.21, p>.05$ ) which suggests that neither sex is perceived to behave more or less respectful than the other when in a leadership position.

Further investigations regarding participants' background and their perceptions of respectful leadership reveal similarly no effects. Neither did participants' education have an impact (Study 2a: $F(8,219)=1.75, p>.05$; Study 2b: $F(9,402)=0.44, p>.05)$, nor were we able to find a correlation between participants' years of work experience and their perceptions of respectful leadership (Study 2a: $r=.12, p>.05$; Study 2b: $r=-.08, p>.05$ ). The same holds true with regard to participants' dyadic tenure spent with the particular leader and perceptions of respectful leadership (Study 2a: $r=.03, p>.05$; Study 2b: $r=-.08, p>.05$ ).

Finally, we find that respectful leadership as assessed by the 12 items is positively related to our surveyed dependent variables, i.e. to participants' identification with their leaders, their appraisal respect for their leaders, their feeling of self-determination, and their job satisfaction. The mean scores, standard deviations, inter-correlations, and internal consistency of the variables for these correlations are summarized in Table 2.

[Insert Table 2 about here]

\section{Discussion}

Previous studies have highlighted that a respectful treatment by authorities leads to beneficial employee behaviour, such as increased cooperation or extra-role behaviour (Boezeman \& Ellemers, 2008a; Lind \& Tyler, 1988; Simon \& Stürmer, 2003; Tyler \& Blader, 2000; Tyler et al., 1997; Tyler \& Lind, 1992). Other studies have highlighted that respectful leadership is also highly desired by employees, yet rarely experienced in organizational practice 
(van Quaquebeke et al., 2008). This latter finding led van Quaquebeke and his colleagues to argue that much organizational potential currently lies idle because of a lack of respectful leadership at the workplace.

To this date, however, the respective research on respect offered only limited insights into which specific leadership behaviours would lead to subordinates perceiving themselves as being treated respectfully. The objective of the present set of studies was therefore a) to present insights as to what respectful leadership actually is, b) to offer a feasible measure for the same to be used in organizational research, and c) to explore some of the effects of such leadership on subordinates.

To accomplish point a), we collected and content analyzed narrations of critical incidents of respectful leadership. Given the size and heterogeneousness of our sample $\left(N_{l}=426\right)-$ from the perspective of qualitative studies - one can assume that the present study was able to establish a sufficiently broad spectrum of possible behaviours and attitudes of respectful leadership. Based upon these narrations, we were able to identify and standardize 149 statements about what respectful leadership entails (printed in full in Appendix A), that can be allocated to 19 categories of respectful leadership. In this respect, the behavioural inventory offers a wellstructured overview on concrete leadership behaviours that are perceived as respectful from the perspective of a subordinate.

To accomplish point b), we subsequently reduced the comprehensive list of respectful leadership behaviours to a more feasible one by means of further qualitative and quantitative analyses. These suggest that a scale of 12 items assesses the construct of respectful leadership well and with satisfactory psychometric properties.

To accomplish point c), we finally explored how perceptions of respectful leadership 
along the developed measure relate to subordinates' identification with their leaders, their appraisal respect for their leaders, their job satisfaction, and their feeling of self-determination. As was expected, perceived respectful leadership correlated strongly with the degree to which participants identified with or showed appraisal respect for their leaders. Both are indicators for subordinates' vertical followership. These results thus suggest that the more subordinates feel respected by their leaders, the more they will "return the favor" by being open to their leader's influence. In addition, the positive correlation between respectful leadership and subordinates' perceptions of self-determination suggests that respectful leadership also entails a message about the subordinates' autonomy, competence, and relatedness - which are important prerequisites for subordinates' independent and proactive reacting to changing organizational circumstances (contextual followership, cf. Deci \& Ryan, 2000; Gagné \& Deci, 2005). Finally, these results are rounded off by the finding that perceived respectful leadership was also related to participants' job satisfaction. This lends more weight to previous findings in that employees not only highly desire respectful leadership (van Quaquebeke et al., 2008) but are also more satisfied when they perceive respectful leadership at the workplace (cf. Baard et al., 2004).

However, even though we believe that the present paper managed to fulfil the specified objectives, the set of studies is not without limitations. In the present paper, we, for instance, did not investigate the relationship of respectful leadership and other established leadership constructs in the field. Indeed, a future line of research should investigate whether and to what extent respectful leadership might be represented as part of leader-member exchange (Graen \& Uhl-Bien, 1995), transformational or charismatic leadership (Bass \& Riggio, 2006), or the recently rediscovered aspects of consideration and task initiation in leadership (Judge, Piccolo, \& Ilies, 2004). Such research should be able to pinpoint the distinctive specifics of each leadership 
style not only by investigating the respective intercorrelations but also by investigating and possibly differentiating different social functions underlying each leadership style.

Furthermore, while it is sensible from a theoretical standpoint to take a follower-centric perspective to investigate the contents and impact of respectful leadership, this approach is also prone for common source biases (Podsakoff, Podsakoff, MacKenzie, \& Lee, 2003). The exclusive use of the input from employees can be perceived as a methodical weak spot in the present paper. Indeed, the strength of our correlation in the second set of studies should be interpreted cautiously as some of the shared variance might be due to the present follower-centric design. For future studies, it would thus be interesting to complement followers' assessments of respectful leadership with self-assessments from their leaders. For one, this could be done in a qualitative design, to investigate whether definitions of respectful leadership might vary between subordinates and their leaders, but it could also be undertaken in a quantitative design to investigate when and why subordinates and leaders might differ in their assessments of respectful leadership behaviour and the effects of such differences on subordinates' subsequent organizational behaviour.

Finally, it should be noted that the present data were collected in Germany. As previous studies indicate that work practices differ considerably between countries (Chhokar, Brodbeck, \& House, 2007; Hofstede, 1991; House, Hanges, Javidan, Dorfman, \& Gupta, 2004), the here obtained results should only be seen as first evidence for what is considered respectful in Western cultures. Indeed, in light of studies which investigate leader prototypes (House et al., 2004), it seems possible that Eastern cultures might, for instance, also value "ensures my face saving", i.e., a leader who ensures that his/her subordinates never loose their face in public, as part of a respectful leadership. For future, more cross-culturally oriented research it thus seems 
interesting to explore on which aspects different cultures' understandings of respectful leadership match and on which they diverge.

Respectful leadership is certainly a fascinating topic to shed further light upon. Evidently, as employees often perceive their supervisors to lack respect for them, there is much potential waiting to be lifted for the benefit of organizations and employees alike. 


\section{Appendix A}

\section{Inventory for Respectful Leadership Behaviour}

The Leader..

Trusting

... shows trust in me as a person.

... trusts my ability to independently and self-reliantly perform well.

... trusts my skills and competencies.

... trusts in me that I do not abuse my degrees of freedom.

... shows me as much trust as I deserve.

\section{Conferring responsibility}

... confers responsibility for important duties on me.

... confers responsibility on me which is matched with my performance.

... confers responsibility for particularly challenging tasks on me.

... enables me to work autonomously.

.... confers adequate responsibility for my work tasks on me.

... quickly confers a lot of responsibility on me.

Considering needs

... responds to my wishes as far as possible.

... is aware of my interests and preferences.

... respects my personal needs.

.... takes my wishes into account beyond what is typical.

... takes my individual particularities into consideration.

Maintaining distance

... accepts my opinion even if it differs considerably from his/her own.

... respects my privacy.

... maintains an appropriate level of distance in our professional relationship.

... never behaves inappropriately, even in jest.

... does not take his/her moods out on me.

Appreciating

\section{Granting autonomy}

... grants me as much freedom as possible to organize my working hours.

... grants me as much freedom as possible for finishing my duties. ... asks me before enlisting me in additional work.

... discusses changes to my duties or deadlines with me.

... allows me to arrange the content and structure of my work as far as possible according to my own wishes.

... gives me freedom to pursue my creative ideas.

... gives me the feeling of being free from control and supervision.

... promotes independent working.

... delegates the decisions relevant for my area of work to me.

\section{Being error-friendly}

... lets me explain myself first if he/she thinks that a mistake has been made.

... acknowledges that mistakes can happen at work. ... does not bring up old mistakes over and over again. ... does not criticize me in front of other people.

... does not denigrate me as a person when I have made a mistake.

... gives me the opportunity to learn from my mistakes and experiences.

... expresses criticism in an objective and constructive way.

Acknowledging equality

... perceives me as of equal worth.

...treats me as of equal worth on the professional level.

... displays at least as much commitment as he/she expects from me.

... adheres him-/herself to the rules and agreements he/she has set.

... creates a feeling of mutual dependence.

... does not stress his/her formally higher status.

... recognizes me as a full-fledged counterpart. 


\begin{tabular}{|c|c|}
\hline ... recognizes my work. & ... awards me with the same rights and privileges. \\
\hline ... praises me when I show a good performance. & ... does not abuse his higher position. \\
\hline $\begin{array}{l}\text {... rewards me for good performance (e.g., a raise, } \\
\text { award, or bonus). }\end{array}$ & Promoting development. \\
\hline ... appreciates even very small successes. & ... advises and actively supports me in my career. \\
\hline ... ensures a justified level of remuneration. & $\begin{array}{l}\text {... does not obstruct me in my career because of } \\
\text { his/her own interests. }\end{array}$ \\
\hline ... appreciates my performance appropriately. & $\begin{array}{l}\text {... supports me by gradually delegating more } \\
\text { responsibility. }\end{array}$ \\
\hline $\begin{array}{l}\text {.. rewards special successes or performance } \\
\text { appropriately. }\end{array}$ & $\begin{array}{l}\text {.. offers me opportunities for professional } \\
\text { development. }\end{array}$ \\
\hline $\begin{array}{l}\text {... rewards special commitment and does not presume } \\
\text { it to be natural. }\end{array}$ & $\begin{array}{l}\text {... fosters my career's progress by arranging } \\
\text { important contacts. }\end{array}$ \\
\hline ... shows appreciation even for routine work. & $\begin{array}{l}\text {... promotes my development even if it offers no } \\
\text { tangible benefits for the company. }\end{array}$ \\
\hline $\begin{array}{l}\ldots \text { is honest and genuine in his/her praise and } \\
\text { appreciation. }\end{array}$ & Excavating potential \\
\hline ... recognizes professional competence. & $\begin{array}{l}\text {... shows a genuine interest in my opinions and } \\
\text { assessments. }\end{array}$ \\
\hline $\begin{array}{l}\text {... gives me the feeling of doing valuable and } \\
\text { worthwhile work in my function. }\end{array}$ & $\begin{array}{l}\text {.. encourages me to express criticism and offer my } \\
\text { own ideas. }\end{array}$ \\
\hline ... praises me and my work to other people. & ... allows me to express my suggestions and ideas. \\
\hline $\begin{array}{l}\text {.. does not sell my performance as his own, but } \\
\text { acknowledges my role appropriately. }\end{array}$ & $\begin{array}{l}\text {... challenges me to make full use of my skills and } \\
\text { competencies. }\end{array}$ \\
\hline $\begin{array}{l}\text {...makes sure that my good performance is also } \\
\text { recognized in higher circles. }\end{array}$ & $\begin{array}{l}\ldots \text { involves him-/herself seriously with my } \\
\text { suggestions and ideas. }\end{array}$ \\
\hline Being open to advice & $\begin{array}{l}\text {... enables me to learn new and interesting things at } \\
\text { my work. }\end{array}$ \\
\hline $\begin{array}{l}\ldots \text { asks for my help even in areas that he/she is } \\
\text { familiar with. }\end{array}$ & $\begin{array}{l}\text {... uses me appropriately according to my skills and } \\
\text { competencies. }\end{array}$ \\
\hline ... trusts my advice in certain areas. & $\begin{array}{l}\text {... enables me to grow with my work and become } \\
\text { more competent. }\end{array}$ \\
\hline $\begin{array}{l}\ldots \text { accepts good ideas and suggestions and puts them } \\
\text { to use accordingly. }\end{array}$ & $\begin{array}{l}\text {... accepts my input with no regard for my position or } \\
\text { formal qualification. }\end{array}$ \\
\hline ... allows him-/herself to be influenced by me. & $\begin{array}{l}\ldots \text { is ready for a professional discussion if there is a } \\
\text { clash of opinions. }\end{array}$ \\
\hline ... shows a basic readiness for learning from me. & Seeking participation \\
\hline $\begin{array}{l}\ldots \text { is ready to rethink his/her opinion if he/she is } \\
\text { confronted with good arguments. }\end{array}$ & $\begin{array}{l}\ldots \text { asks for my opinion before he/she takes crucial } \\
\text { decisions. }\end{array}$ \\
\hline $\begin{array}{l}\ldots \text { accepts that I am more competent in certain areas } \\
\text { than he/she is. }\end{array}$ & $\begin{array}{l}\text {... takes certain decisions only on the basis of my } \\
\text { judgment. }\end{array}$ \\
\hline Accepting criticism & $\begin{array}{l}\text {... appropriately involves me in decisions that affect } \\
\text { my work or work environment. }\end{array}$ \\
\hline ... accepts that I voice my criticism. & $\begin{array}{l}\ldots \text { is ready to rethink his/her ideas if he/she is given } \\
\text { good reason to do so. }\end{array}$ \\
\hline ... accepts justified criticism. & $\begin{array}{l}\text {.. gives me the opportunity to voice my opinion on } \\
\text { decisions that affect me. }\end{array}$ \\
\hline ... apologizes for inappropriate behaviour towards me. & Taking interest on a personal level \\
\hline
\end{tabular}




\begin{tabular}{|c|c|}
\hline $\begin{array}{l}\text {... changes his/her behaviour accordingly if given } \\
\text { justified criticism. }\end{array}$ & $\begin{array}{l}\text {... reacts appropriately to special incidents in my } \\
\text { private life (e.g., a death in the family, marriage, etc.) }\end{array}$ \\
\hline ... admits to own mistakes. & $\ldots$ is interested in my wellbeing. \\
\hline $\begin{array}{l}\text {... does not try to hold me responsible for his/her own } \\
\text { mistakes. }\end{array}$ & ... talks to me about private and personal matters. \\
\hline Showing loyalty & $\ldots$ is ready for concessions in times of personal crisis. \\
\hline $\begin{array}{l}\text {... unequivocally stands up for me and my work } \\
\text { against third parties. }\end{array}$ & $\begin{array}{l}\text {... demonstrates genuine interest in me as a person } \\
\text { and not just a worker. }\end{array}$ \\
\hline $\begin{array}{l}\text {... stands by my decisions and defends them, if } \\
\text { necessary, towards other people. }\end{array}$ & ... offers help in case of personal problems. \\
\hline ... backs me up in critical situations. & $\begin{array}{l}\text {... maintains a personal relationship with me even } \\
\text { outside of work. }\end{array}$ \\
\hline $\begin{array}{l}\text {.. accepts responsibility for mistakes that were made } \\
\text { because of a lack of support. }\end{array}$ & $\ldots$ is interested in a good working relationship. \\
\hline ... defends my interests against other people. & Supporting \\
\hline Being attentive & ...is available for my questions and problems. \\
\hline ... listens to me when I am speaking. & ... helps me solve difficult tasks on my own. \\
\hline ... prepares properly for talks with me. & ... helps me redress past mistakes. \\
\hline$\ldots$ is interested in my work. & $\begin{array}{l}\text {... provides the required means and resources to } \\
\text { enable me to produce good work. }\end{array}$ \\
\hline ... does not interrupt me. & ... supports me when dealing with other people. \\
\hline ... gives me appropriate answers for my questions. & ... reviews my work situation together with me. \\
\hline$\ldots$ is always available in urgent cases. & $\begin{array}{l}\ldots \text { provides me with any information that is relevant } \\
\text { to me. }\end{array}$ \\
\hline ... takes enough time for me. & ... challenges, but does not overburden me. \\
\hline ... takes me and my work seriously. & $\begin{array}{l}\text {.. recognizes and promotes my strong points instead } \\
\text { of being fixated on my weaknesses. }\end{array}$ \\
\hline ... can see my point of view. & $\begin{array}{l}\text {... asks regularly about my work without creating a } \\
\text { feeling of having to justify myself. }\end{array}$ \\
\hline$\ldots$ is open for my concerns. & ... gets his/her hands dirty if it is necessary. \\
\hline $\begin{array}{l}\text {.. lets me be true to myself and does not force me to } \\
\text { pretend anything. }\end{array}$ & $\begin{array}{l}\ldots \text { is personally committed to me and my field of } \\
\text { work. }\end{array}$ \\
\hline Being reliable & ... promotes a good working climate. \\
\hline ... interacts in an open and honest way with me. & $\ldots$ tries to motivate me. \\
\hline $\begin{array}{l}\ldots \text { gives comprehensible reasons and explanations for } \\
\text { his/her decisions. }\end{array}$ & ... offers me honest feedback when I need it. \\
\hline $\begin{array}{l}\text {... expresses his/her expectations clearly and } \\
\text { transparently. }\end{array}$ & Interacting friendly \\
\hline$\ldots$ is punctual. & $\ldots$ is friendly towards me. \\
\hline ... treats me justly. & ... treats me in a polite manner. \\
\hline ... does not have any unjustified favourites. & ... shows his/her empathy for me. \\
\hline$\ldots$ adheres to agreements. & ... has a sense of humour. \\
\hline$\ldots$ treats me in a fair way. & $\ldots$ treats me in a constructive and cooperative way. \\
\hline $\begin{array}{l}\text {... behaves predictably so that I always know where I } \\
\text { stand. }\end{array}$ & ... converses in a calm tone of voice. \\
\hline
\end{tabular}




\section{References}

Anderson, E. (1993). Value in ethics and economics. Cambridge, MA: Harvard University Press.

Baard, P. P., Deci, E. L., \& Ryan, R. M. (2004). Intrinsic need satisfaction: A motivational basis of performance and well-being in two work settings. Journal of Applied Social Psychology, 34, 2045-2068.

Bass, B. M., \& Riggio, R. E. (2006). Transformational leadership (2nd ed.). Mahwah, NJ, US: Lawrence Erlbaum Associates Publishers.

Bettencourt, B. A., \& Miller, N. (1996). Sex differences in aggression as a function of provocation: a meta-analysis. Psychological Bulletin, 119, 422-227.

Birch, T. H. (1993). Moral considerability and universal consideration. Environmental Ethics, $15,313-332$.

Boeckmann, R. J., \& Tyler, T. R. (2002). Trust, respect and the psychology of political engagement. Journal of Applied Social Psychology, 32, 2067-2088.

Boezeman, E. J., \& Ellemers, N. (2007). Volunteering for charity: Pride, respect, and the commitment of volunteers. Journal of Applied Psychology, 92, 771-785.

Boezeman, E. J., \& Ellemers, N. (2008a). Pride and respect in volunteers' organizational commitment. European Journal of Social Psychology, 38, 159-172.

Boezeman, E. J., \& Ellemers, N. (2008b). Volunteer recruitment: The role of organizational support and anticipated respect in non-volunteers' attraction to charitable volunteer organizations. Journal of Applied Psychology, 93, 1013-1026.

Branscombe, N. R., Spears, R., Ellemers, N., \& Doosje, B. (2002). Intragroup and intergroup evaluation effects on group behavior. Personality \& Social Psychology Bulletin, 28, 744753. 
Brennan, R. L., \& Prediger, D. J. (1981). Coefficient kappa: some uses and misuses, and alternatives. Educational and Psychological Measurement, 41, 687-699.

Chemers, M. M. (2003). Leader effectiveness: An integrative review. In M. A. Hogg \& R. S. Tindale (Eds.), Blackwell handbook of social psychology: Group processes (pp. 376399). Malden, MA: Blackwell Publisher.

Chhokar, J. S., Brodbeck, F. C., \& House, R. J. (Eds.). (2007). Culture and leadership across the world: The GLOBE book of in-depth studies of 25 societies. Mahwah, NJ: LEA Publishers.

Cohen, D., Nisbett, R. E., Bowdle, B. F., \& Schwarz, N. (1996). Insult, aggression, and the southern culture of honor: an "experimental ethnography". Journal of Personality \& Social Psychology, 70, 945-960.

De Cremer, D. (2003). Noneconomic motives predicting cooperation in public good dilemmas: The effect of received respect on contributions. Social Justice Research, 16, 367-377.

De Cremer, D., \& Tyler, T. (2005). A matter of intragroup status: The importance of respect for the viablity of groups. In M. Thomas-Hunt (Ed.), Research on managing groups and teams (Vol. 7, pp. 1-21). Greenwich. CT: Elsevier Science Press.

Deci, E. L., \& Ryan, R. M. (2000). The "what" and "why" of goal pursuits: Human needs and the self-determination of behavior. Psychological Inquiry, 11, 227-268.

Dillon, R. S. (2003). Respect. The Stanford Encyclopedia of Philosophy Fall 2003 Edition. Retrieved October 05, 2004, from http://plato.stanford.edu/archives/fall2003/entries/respect/

Dillon, R. S. (2007). Respect: A philosophical perspective Gruppendynamik und Organisationsberatung, 38, 201-212. 
Downie, R. S., \& Telfer, E. (1969). Respect for Persons. London: George Allen\&Unwin.

Ellingsen, T., \& Johannesson, M. (2007). Paying respect. Journal of Economic Perspectives, 21, 135-149.

Frankena, W. K. (1986). The ethics of respect for persons. Philosophical Topics, 14, 149-167.

Gagné, M., \& Deci, E. L. (2005). Self-determination theory and work motivation. Journal of Organizational Behavior, 26, 331-362.

Goldstein, D. K., \& Rockart, J. F. (1984). An examination of work-related correlates of job satisfaction in programmer/analysts. MIS Quarterly, 8, 103-115.

Graen, G. B., \& Uhl-Bien, M. (1995). Relationship-based approach to leadership: Development of leader-member exchange (LMX) theorie of leadership over 25 years: Applying a multi-level multi-domain approach. The Leadership Quarterly, 6, 219-247.

Graf, M. M., \& van Quaquebeke, N. (2007). Respected leaders: A question of accepted influence, personal power/legitimacy, and personal identification. Paper presented at the 13th European Congress on Work and Organizational Psychology, Stockholm.

Hill, T. E., Jr. (1998). Respect for persons. In E. Craig (Ed.), Routledge Encyclopedia of Philosophy. London: Routledge.

Hofstede, G. H. (1991). Cultures and organizations: Software of the mind. London, New York: McGraw-Hill.

House, R. J., Hanges, P. J., Javidan, M., Dorfman, P., \& Gupta, V. (2004). Culture, leadership, and organizations: The GLOBE study of 62 societies. Thousand Oaks, CA: Sage Publications.

Judge, T. A., Piccolo, R. F., \& Ilies, R. (2004). The forgotten ones? The validity of consideration and initiating structure in leadership research. Journal of Applied Psychology, 89, 36-51. 
Kant, I. (1788). Critic der practischen Vernunft. Riga Johann Friedrich Hartknoch.

Kelman, H. C. (1958). Compliance, identification, and internalization: Three processes of attitude change. Journal of Conflict Resolution, 2, 51-60.

Kunin, T. (1955). The Construction of a New Type of Attitude Measure. Personal Psychology: A Journal of Applied Research, 8, 65-77.

La Guardia, J. G., Ryan, R. M., Couchman, C. E., \& Deci, E. L. (2000). Within-person variation in security of attachment: A self-determination theory perspective on attachment, need fulfillment, and well-being. Journal of Personality and Social Psychology, 79, 367-384.

Lind, E. A., \& Tyler, T. R. (1988). The social psychology of procedural justice. New York: Plenum.

Mael, F. A., \& Ashforth, B. E. (1992). Alumni and their alma mater: A partial test of the reformulated model of organizational identification. Journal of Organizational Behavior, 13, 103-123.

Margalit, A. (1998). The decent society (N. Goldblum, Trans.). Cambridge, MA: Harvard University Press.

Mason, E. S. (1994). Work values: A gender comparison and implications for practice. Psychological Reports, 74, 415-418.

Mayring, P. (2000). Qualitative content analysis. Forum Qualitative Social Research, 1.

Miller, D. T. (2001). Disrespect and the experience of injustice. Annual Review of Psychology, $52,527-552$.

Organ, D. W., Podsakoff, P. M., \& MacKenzie, S. B. (2006). Organizational Citizenship Behavior: Its nature, antecedents, and consequences. Thousand Oaks: Sage Publications.

Pettit, P. (1989). Consequentialism and respect for persons. Ethics, 100, 116-126. 
Podsakoff, P. M., Podsakoff, N. P., MacKenzie, S. B., \& Lee, J.-Y. (2003). Common method biases in behavioral research: A critical review of the literature and recommended remedies. Journal of Applied Psychology, 88, 879 - 903.

Rawls, J. (1999). A theory of justice. Cambridge, MA: Harvard University Press.

Raz, J. (2001). Value, respect and attachment (Vol. 4). Cambridge: Cambridge University Press.

Sennett, R. (2003). Respect in a world of inequality (1st ed.). New York: W.W. Norton.

Shamir, B., House, R. J., \& Arthur, M. B. (1993). The motivational effects of charismatic leadership: A self-concept-based theory. Organization Science, 4, 577-594.

Simon, B. (2007). Respect, equality, and power: A social psychological perspective. Gruppendynamik und Organisationsberatung, 38, 309-326.

Simon, B., Lücken, M., \& Stürmer, S. (2006). The added value of respect: Reaching across inequality. British Journal of Social Psychology, 45, 535-546.

Simon, B., \& Stürmer, S. (2003). Respect for group members: Intragroup determinants of collective identification and group-serving behavior. Personality \& Social Psychology Bulletin, 29, 183-193.

Simon, B., \& Stürmer, S. (2005). In search of the active ingredient of respect: A closer look at the role of acceptance. European Journal of Social Psychology, 35, 809-818.

Sleebos, E., Ellemers, N., \& De Gilder, D. (2007). Explaining the motivational forces of (dis)respect: How self-focused and group-focused concerns can result in the display of group-serving efforts. Gruppendynamik und Organisationsberatung, 38, 327-342.

Smith, H. J., Tyler, T. R., Huo, Y. J., Ortiz, D. J., \& Lind, E. A. (1998). The self-relevant implications of the group-value model: Group membership, self-worth, and treatment quality. Journal of Experimental Social Psychology, 34, 470-493. 
Spears, R., Ellemers, N., \& Doosje, B. (2005). Let me count the ways in which I respect thee: Does competence compensate or compromise lack of liking from the group? European Journal of Social Psychology, 35, 263-279.

Strauss, A. L., \& Corbin, J. M. (1998). Basics of qualitative research: Techniques and procedures for developing grounded theory ( $2 \mathrm{nd} \mathrm{ed}$.): Sage.

Thompson, W. D., \& Walter, S. D. (1988). A reappraisal of the kappa coefficient. Journal of Clinical Epidemiology, 41, 949-958.

Tyler, T. R., \& Blader, S. L. (2000). Cooperation in groups: Procedural justice, social identity, and behavioral engagement. Philadelphia: Psychology press.

Tyler, T. R., \& Blader, S. L. (2003). The group engagement model: Procedural justice, social identity, and cooperative behavior. Personality \& Social Psychology Review, 7, 349-361.

Tyler, T. R., Boeckmann, R. J., Smith, H. J., \& Huo, Y. J. (1997). Social justice in a diverse society. Boulder, CO: Westview.

Tyler, T. R., \& Lind, E. A. (1992). A relational model of authority in groups. In M. P. Zanna (Ed.), Advances in Experimental Social Psychology (Vol. 25, pp. 115-191). New York: Academic Press.

van Dick, R., Wagner, U., Stellmacher, J., \& Christ, O. (2004). The utility of a broader conceptualization of organizational identification: Which aspects really matter? Journal of Occupational \& Organizational Psychology, 77, 171-191.

van Knippenberg, B., \& van Knippenberg, D. (2003). Leadership, identy and influence:

Relational concerns in the use of influence tactics. In D. van Knippenberg \& M. A. Hogg (Eds.), Leadership and power: Identity processes in groups and organizations (pp. 123137). London: Sage. 
van Knippenberg, D., van Knippenberg, B., De Cremer, D., \& Hogg, M. A. (2004). Leadership, self, and identity: A review and research agenda. The Leadership Quarterly, 15, 825-856. van Quaquebeke, N., \& Brodbeck, F. C. (2008). Entwicklung und erste Validierung zweier Instrumente zur Erfassung von Führungskräfte-Kategorisierung im deutschsprachigen Raum [Development and first validation of two scales to measure leader categorization in German-speaking countries]. Zeitschrift für Arbeits- und Organisationspsychologie, 52, 70-80.

van Quaquebeke, N., Henrich, D. C., \& Eckloff, T. (2007). “It's not tolerance I'm asking for, it's respect!" A conceptual framework to differentiate between tolerance, acceptance and respect. Gruppendynamik und Organisationsberatung, 38, 185-200.

van Quaquebeke, N., Zenker, S., \& Eckloff, T. (2008). Find out how much it means to me! The importance of interpersonal respect in work values compared to perceived organizational practices. Journal of Business Ethics

Yukl, G. A., \& Van Fleet, D. D. (1992). Theory and research on leadership in organizations. In M. D. Dunnette \& L. M. Hough (Eds.), Handbook of industrial and organizational psychology (5th ed., Vol. 1, pp. 147-198). Palo Alto, CA: Consulting Psychologists Press. 
Table 1

Psychometric Properties of Each Item of the Respectful Leadership Scale in Study $2 a$ and $2 b$

Items’ Psychometric Properties When Answered

With Regard to Participants' Current Leader

Mean

Importance
Correlation

with Marker Factor Discriminatory

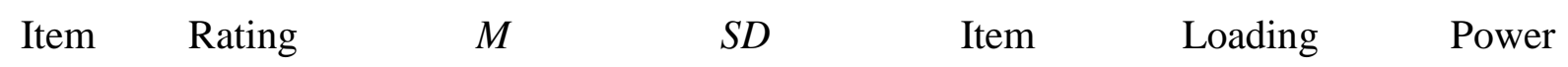
$\begin{array}{llllllllllll}2 \mathrm{a} & 2 \mathrm{~b} & 2 \mathrm{a} & 2 \mathrm{~b} & 2 \mathrm{a} & 2 \mathrm{~b} & 2 \mathrm{a} & 2 \mathrm{~b} & 2 \mathrm{a} & 2 \mathrm{~b} & 2 \mathrm{a} & 2 \mathrm{~b}\end{array}$

\begin{tabular}{llllllllllll}
\hline 1. & 6.43 & 6.45 & 4.12 & 4.13 & 1.01 & 0.97 & $.67^{* * *} .70^{* * *}$ & .71 & .74 & .67 & .69 \\
2. & 6.41 & 6.49 & 3.50 & 3.61 & 1.28 & 1.24 & $.70^{* * *} .68^{* * *}$ & .81 & .80 & .77 & .76 \\
3. & 6.34 & 6.14 & 3.59 & 3.51 & 1.38 & 1.28 & $.77^{* * *} .76^{* * *}$ & .85 & .85 & .82 & .82 \\
4. & 6.11 & 6.17 & 3.52 & 3.70 & 1.25 & 1.11 & $.75^{* * *} .70^{* * *}$ & .84 & .83 & .81 & .79 \\
5. & 6.09 & 5.94 & 3.35 & 3.46 & 1.33 & 1.23 & $.75^{* * *} .72^{* * *}$ & .88 & .85 & .85 & .81 \\
6. & 6.42 & 6.37 & 3.57 & 3.68 & 1.38 & 1.36 & $.55^{* * *} .62^{* * *}$ & .70 & .78 & .65 & .73 \\
7. & 6.02 & 6.00 & 3.35 & 3.40 & 1.32 & 1.28 & $.74^{* * *} .69^{* * *}$ & .84 & .81 & .81 & .77 \\
8. & 6.07 & 6.00 & 3.96 & 4.04 & 1.06 & 0.99 & $.66^{* * *} .66^{* * *}$ & .80 & .79 & .76 & .75 \\
9. & 6.24 & 6.08 & 3.06 & 3.20 & 1.32 & 1.27 & $.67^{* * *} .60^{* * *}$ & .80 & .74 & .76 & .69 \\
10. & 6.28 & 6.14 & 3.63 & 3.74 & 1.22 & 1.14 & $.81^{* * *} .76^{* * *}$ & .90 & .89 & .87 & .86 \\
11. & 6.40 & 6.30 & 3.60 & 3.73 & 1.24 & 1.15 & $.73^{* * *} .73^{* * *}$ & .85 & .85 & .82 & .81 \\
12. & 6.47 & 6.31 & 3.68 & 3.77 & 1.22 & 1.13 & $.81^{* * *} .77^{* * *}$ & .90 & .87 & .88 & .84
\end{tabular}

Note. $N_{2 a}=228 ; N_{2 b}=412 ; * * * p<.001$. 
Table 2

Mean Scores, Standard Deviations, Intercorrelations, and Internal Consistencies of the Variables in Study $2 a$ and $2 b$

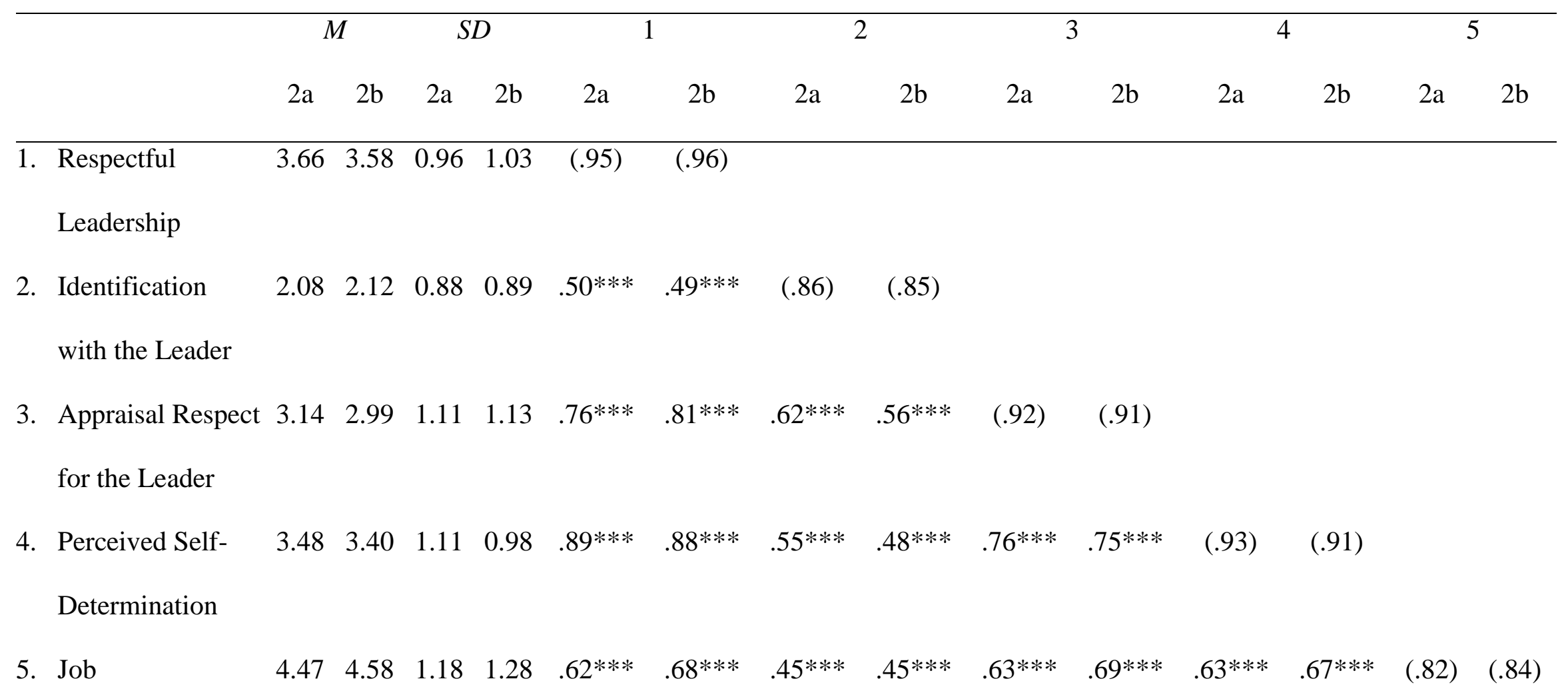

Satisfaction

Note. $N_{2 a}=228 ; N_{2 b}=412$; values written in brackets are each scale's Cronbach's $\alpha ; * * * p<.001$. 


\section{Publications in the ERIM Report Series Research* in Management}

\section{ERIM Research Program: "Organizing for Performance"}

\section{9}

On the Specification of the Gravity Model of Trade: Zeros, Excess Zeros and Zero-Inflated Estimation

Martijn J. Burger, Frank G. van Oort, and Gert-Jan M. Linders

ERS-2009-003-ORG

http://hdl.handle.net/1765/14614

The Current State of Research on Networks in China's Business System

Johannes Meuer and Barbara Krug

ERS-2009-007-ORG

http://hdl.handle.net/1765/14842

Encountered Problems and Outcome Status in Nascent Entrepreneurship

A. Marco van Gelderen, B. Pankaj Patel, and A. Roy Thurik

ERS-2009-008-ORG

http://hdl.handle.net/1765/14913

The Ethics of Organizations: A Longitudinal Study of the U.S. Working Population

Muel Kaptein

ERS-2009-018-ORG

http://hdl.handle.net/1765/15405

From Symbolic to Substantive Documents: When Business Codes of Ethics Impact Unethical Behavior in the Workplace Muel Kaptein

ERS-2009-021-ORG

http://hdl.handle.net/1765/15909

Knowledge Management as a Strategic Tool to Foster Innovativeness of SMEs

Haibo Zhou, and Lorraine Uhlaner

ERS-2009-025-ORG

http://hdl.handle.net/1765/15913

Knowledge Management in the SME and its Relationship to Strategy, Family Orientation and Organization Learning Haibo Zhou, and Lorraine Uhlaner

ERS-2009-026-ORG

http://hdl.handle.net/1765/15914

Defining Respectful Leadership: What it is, how it can be measured, and another glimpse at what it is related to Niels van Quaquebeke, and Tilman Eckloff ERS-2009-027-ORG

http://hdl.handle.net/1765/15942

* A complete overview of the ERIM Report Series Research in Management: https://ep.eur.nl/handle/1765/1

ERIM Research Programs:

LIS Business Processes, Logistics and Information Systems

ORG Organizing for Performance

MKT Marketing

F\&A Finance and Accounting

STR Strategy and Entrepreneurship 